\title{
Pressure Effects on Elastic Properties and Glass Transition of Zr-, Pd-based Bulk Metallic Glasses
}

\author{
W. K. Wang \\ ${ }^{1}$ Center for Condensed Matter Physics, Institute of Physics, Chinese Academy of Sciences, Beijing, 100080, \\ People's Republic of China \\ ${ }^{2}$ College of Material Sciences and Chemical Engineering, Yanshan University, Qinhuangdao, 066004, \\ People's Republic of China
}

The structures and properties of materials are profoundly altered under high pressure due to a large change of atom spacing, chemical bonding and Gibbs free energies. Therefore, materials with novel structures and properties can be created via a process known as pressureinduced phase transition. Here we report the investigations of pressure effects on the elastic properties and the glass transition of $\mathrm{Zr}-$, Pd-based bulk metallic glasses (BMGs). The elastic constants and the Debye temperatures, of a $\mathrm{Zr}_{41} \mathrm{Ti}_{14} \mathrm{Cu}_{12.5} \mathrm{Ni}_{10} \mathrm{Be}_{22.5} \mathrm{C}_{1}$ and a $\mathrm{Pd}_{39} \mathrm{Ni}_{10} \mathrm{Cu}_{30} \mathrm{P}_{21}$ BMGs are measured by using an ultrasonic technique, and their pressure dependence is exhibited. The equations of state (EOS) of the two BMGs are established. The acoustic attenuation behaviors are also monitored with various pressure in the two BMGs, and a marked difference between the two BMGs is revealed. The effects of pressure-induced structural relaxation on the glass transition of the $\mathrm{Pd}_{39} \mathrm{Ni}_{10} \mathrm{Cu}_{30} \mathrm{P}_{21}$ BMG are investigated by a temperature-modulated differential scanning calorimetry technique. The pressure dependence of the reversible and irreversible glass transition is explained.

(Received December 6, 2000: Accepted February 1, 2001)

Keywords: bulk metallic glasses, phase transition, elastic constants, ultrasonic attenuation, glass transition, high pressure

\section{Introduction}

Metallic glasses have been a subject of continued interest for decades with their unusual properties such as high fracture strength, excellent soft magnetic properties, good corrosion resistance and anomalous electronic transport properties. ${ }^{1,2)}$ However, in comparison with crystalline, the understanding on glassy metallic state has been impeded by the inability in preparing bulk metallic glasses (BMGs). Recently, multicomponent Pd- and Zr-based BMGs with a larger geometry size have been developed by a conventional casting process at a low cooling rate. ${ }^{3-6)}$ The BMGs are of excellent glass forming ability (GFA) and wide supercooled liquid regions (SLR). Among the BMGs, ZrTi- and PdNi-based systems exhibit the best GFA and the highest reduced glass transition temperature up to 0.72. It is believed that the BMGs have a considerable potential for both theoretical investigations and technological applications. So far, a number of investigations are carried out in various aspects including the establishment of new alloy systems with high GFA, the development of new materials from the BMGs such as nanocrystalline materials, the identification of intrinsic characteristics of metallic glasses such as the mechanism of atomic transport. ${ }^{7-9)}$ However, most results come from the measurement at ambient pressure, not much work is performed on the behaviors and properties of the BMGs under high pressure, in particular, on the understanding of microstructural configurations under pressure. It is known that the structures and properties of materials are profoundly altered under high pressure due to a large change of atom spacing, chemical bonding and Gibbs free energies. Therefore, materials with novel structures and properties can be created via a process known as pressure-induced phase transition. ${ }^{10-12)}$ Atomic transport can be suppressed under pressure during phase transitions, and thus some structural features of metallic glasses have ac- cess to be revealed under high pressure. In previously works, we systematically investigate the phase transformation behaviors of conventional metallic glasses under high pressure. ${ }^{13,14)}$ The larger geometry of the BMGs will be more desirable to further reveal the nature of amorphous state and the transition between the supercooled liquid and glassy state. In the paper, we report some recent results of Zr- and Pd-based BMGs under high pressure. The pressure dependence of elastic constants of $\mathrm{Zr}_{41} \mathrm{Ti}_{14} \mathrm{Cu}_{12.5} \mathrm{Ni}_{10} \mathrm{Be}_{22.5} \mathrm{C}_{1}$ and a $\mathrm{Pd}_{39} \mathrm{Ni}_{10} \mathrm{Cu}_{30} \mathrm{P}_{21}$ $\mathrm{BMG}$ is determined and their equations of state (EOS) are established, respectively. The pressure-induced structural relaxation in the two BMGs is exhibited by the measurements of ultrasonic attenuation. The effects of pressure-induced structural relaxation on the glass transition of the $\mathrm{Pd}_{39} \mathrm{Ni}_{10} \mathrm{Cu}_{30} \mathrm{P}_{21}$ BMG are investigated.

\section{Experimental}

The acoustic velocities and their pressure dependence of the BMGs were measured at room temperature by using the pulse echo overlap method. The experimental details for the acoustic velocity measurements were described in Refs. 15) and 16). Upon pressure loading, the density and the length of the $\mathrm{Zr}_{41} \mathrm{Ti}_{14} \mathrm{Cu}_{12.5} \mathrm{Ni}_{10} \mathrm{Be}_{22.5} \mathrm{C}_{1}$ and the $\mathrm{Pd}_{39} \mathrm{Ni}_{10} \mathrm{Cu}_{30} \mathrm{P}_{21}$ glassy rods were modified with the Richard Cook method. ${ }^{17}$ Elastic constants (e.g., Young's modulus $E$, shear modulus $G$, bulk modulus $K$, and Poisson's ratio $\sigma$ ) and Debye temperatures $\Theta_{\mathrm{D}}$ were derived from the acoustic velocities and the densities. ${ }^{18)}$ The pressure effects on the glass transition of the $\mathrm{Pd}_{39} \mathrm{Ni}_{10} \mathrm{Cu}_{30} \mathrm{P}_{21}$ BMG was invesitgated by using a temperature-modulated differential scanning calorimetry (TMDSC) technique. TMDSC measurements were performed on a TA-2910 instrument at an underlying heating rate of $2 \mathrm{~K} / \mathrm{min}$. The time period for one sinusoidal temperature oscillation was $60 \mathrm{~s}$. The amplitude of the temperature modulation was held constant at $1 \mathrm{~K}$. 
Table 1 Acoustic velocities (longitudinal $v_{\mathrm{l}}$, transverse $v_{s}$ ), Young's modulus $E$, Shear modulus $G$, bulk modulus $K$, Poisson ratio $\sigma$, and Debye temperature $\Theta_{\mathrm{D}}$ of $\mathrm{Zr}_{41} \mathrm{Ti}_{14} \mathrm{Cu}_{12.5} \mathrm{Ni}_{9} \mathrm{Be}_{22.5} \mathrm{C}_{1}$ and $\mathrm{Pd}_{39} \mathrm{Ni}_{10} \mathrm{Cu}_{30} \mathrm{P}_{21}$ bulk metallic glasses.

\begin{tabular}{ccccccccc}
\hline Sample & $v_{1}(\mathrm{~km} / \mathrm{s})$ & $v_{\mathrm{s}}(\mathrm{km} / \mathrm{s})$ & $\rho\left(\mathrm{g} / \mathrm{cm}^{3}\right)$ & $E(\mathrm{GPa})$ & $G(\mathrm{GPa})$ & $K(\mathrm{GPa})$ & $\sigma$ & $\Theta_{\mathrm{D}}(\mathrm{K})$ \\
\hline $\mathrm{Zr}_{41} \mathrm{Ti}_{14} \mathrm{Cu}_{12.5} \mathrm{Ni}_{9} \mathrm{Be}_{22.5} \mathrm{C}_{1}$ & 5.10 & 2.53 & 6.16 & 106.0 & 39.54 & 107.3 & 0.34 & 335 \\
$\mathrm{Pd}_{39} \mathrm{Ni}_{10} \mathrm{Cu}_{30} \mathrm{P}_{21}$ & 4.75 & 1.963 & 9.152 & 98.5 & 35.3 & 159.4 & 0.397 & 280 \\
\hline
\end{tabular}

\section{Results and Discussion}

\subsection{Elastic properties}

The longitudinal, transverse velocities $v_{1}, v_{\mathrm{s}}$, and the density $\rho$ of the $\mathrm{Zr}_{41} \mathrm{Ti}_{14} \mathrm{Cu}_{12.5} \mathrm{Ni}_{9} \mathrm{Be}_{22.5} \mathrm{C}_{1}$ and $\mathrm{Pd}_{39} \mathrm{Ni}_{10} \mathrm{Cu}_{30} \mathrm{P}_{21}$ BMGs at ambient condition are listed in Table 1 as well as the calculated $E, G, K, \sigma$, and $\Theta_{\mathrm{D}} \cdot{ }^{15,16)}$ It is known that $\sigma$ reflects the relative change between the compressive and shear deformation of a solid. For the brittle oxide glasses, since the bonding configurations is difficult and atoms can hardly rearrange themselves to shear strain, $\sigma$ is small and ranges from 0.15 to $0.25 .{ }^{19,20)}$ By contrast, the conventional MGs with poor GFA (the critical cooling rate, $R_{\mathrm{c}}$ for glass formation, which represents the GFA of a glass forming system, ranges from $10^{4}$ to $10^{7} \mathrm{~K} / \mathrm{s}^{1,7,8)}$ ) have higher values $(\geq 0.40),{ }^{21)}$ indicating the ease of atomic rearrangement in these materials. For the novel multicomponent BMGs with excellent GFA, $\sigma$ is smaller than that of the conventional MGs, but bigger than that of the oxide glasses. The BMGs have highly dense random packed structure compared to the conventional MGs, which makes the redistribution of atoms extremely difficult, and leads to the relative small $\sigma$. On the other hand, the GFA of the BMGs (the $R_{\mathrm{c}}$ range from 1 to $100 \mathrm{~K} / \mathrm{s}$ ) is much better than that of the conventional MGs and approaches that of the oxide glasses whose $R_{\mathrm{c}}$ is less than $0.1 \mathrm{~K} / \mathrm{s}$. The relation of $\sigma$ and the $R_{\mathrm{c}}$ of the oxide glasses, BMGs and conventional MGs is shown in Fig. 1. It is clear that $\sigma$ has a close correlation with the GFA of the glassy systems. The glasses with smaller $\sigma$ has higher GFA, indicating close dependence of the GFA on the microstructure of glass forming systems.

Figures 2 and 3 show the pressure dependence of the reduced longitudinal and transverse velocities, $\delta v(P) / v\left(P_{0}\right)=$ $\left(v(P)-v\left(P_{0}\right)\right) / v\left(P_{0}\right)$, for the $\mathrm{Zr}_{41} \mathrm{Ti}_{14} \mathrm{Cu}_{12.5} \mathrm{Ni}_{9} \mathrm{Be}_{22.5} \mathrm{C}_{1}$ and $\mathrm{Pd}_{39} \mathrm{Ni}_{10} \mathrm{Cu}_{30} \mathrm{P}_{21}$ BMGs at room temperature, where $P_{0}$ is the ambient pressure, and $v_{0}$ is the velocity at $P_{0}$. The data are reversible under $P$ cycling though slight hysteresis effects are shown in the $\mathrm{Pd}_{39} \mathrm{Ni}_{10} \mathrm{Cu}_{30} \mathrm{P}_{21} \mathrm{BMG}$. It can be seen that upon loading, $v_{\mathrm{l}}$ and $v_{\mathrm{s}}$ roughly linearly increase. The BMGs have similar pressure dependence of acoustic velocities to steel and tungsten carbide. ${ }^{22)}$ However, for the silicate glasses and amorphous carbon, it is found that $v_{\mathrm{s}}$ decreases with increasing pressure. ${ }^{19)}$ For the two BMGs, the longitudinal velocity is more sensitive to the pressure variation than the transverse one. The corresponding pressure dependence of elastic constants $Y(Y=E, G, K$, and $\sigma)$ of the two BMGs calculated from the velocities are shown in insets of Figs. 2 and 3. $Y$ is normalized by $\delta Y / Y_{0}=\left[Y(P)-Y\left(P_{0}\right)\right] / Y\left(P_{0}\right)$, where $Y_{0}$ is a normal modulus at ambient pressure $P_{0}$. One can see that $E, G, K$, and $\sigma$ monotonically increase with increasing pressure. The increase of elastic constants is attributed to the denser packing microstructure and vibrational anharmonicity

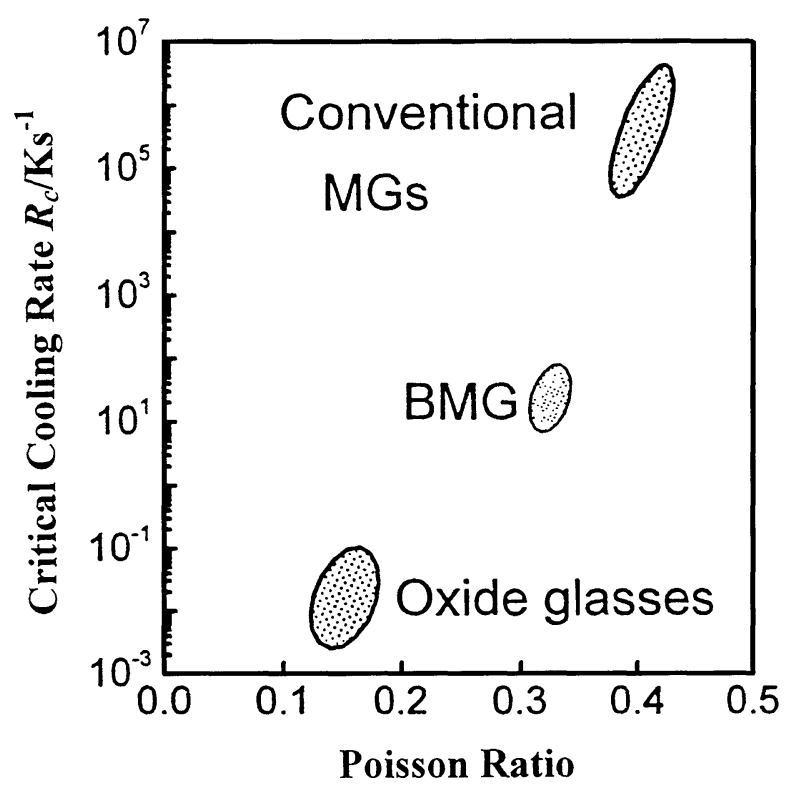

Fig. 1 Relation of critical glass formation cooling rate and Poisson's ratio $\sigma$ for the oxide glasses, conventional MGs and BMGs. The correlation between the $\sigma$ and the GFA of the three types of glasses is clearly seen.

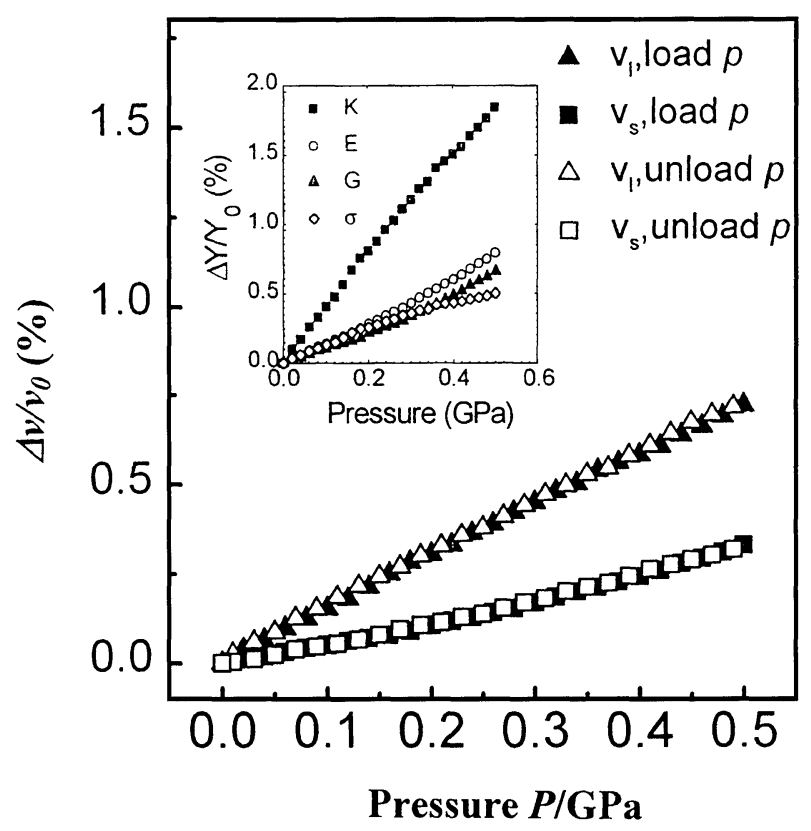

Fig. 2 Variation of longitudinal and transverse velocities of the $\mathrm{Zr}_{41} \mathrm{Ti}_{14} \mathrm{Cu}_{12.5} \mathrm{Ni}_{9} \mathrm{Be}_{22.5} \mathrm{C}_{1} \mathrm{BMG}$ with pressure $\left(v=v_{1}, v_{\mathrm{s}}\right)$ at room temperatue for the first pressure load and unload cycle, $v$ is normalized by $\Delta v / v_{0}=\left(v-v_{0}\right) / v_{0}$, where $v_{0}$ is a normal velocity at ambient pressure $p_{0}$. The inset is the vatriation of elastic constants $Y$ of the BMG $(Y=E$, $G, K, \sigma)$ with pressure, $Y$ is normalized by $\Delta Y / Y_{0}=\left(Y-Y_{0}\right) / Y_{0}$, where $Y_{0}$ is a normal modulus at $p_{0}$. 


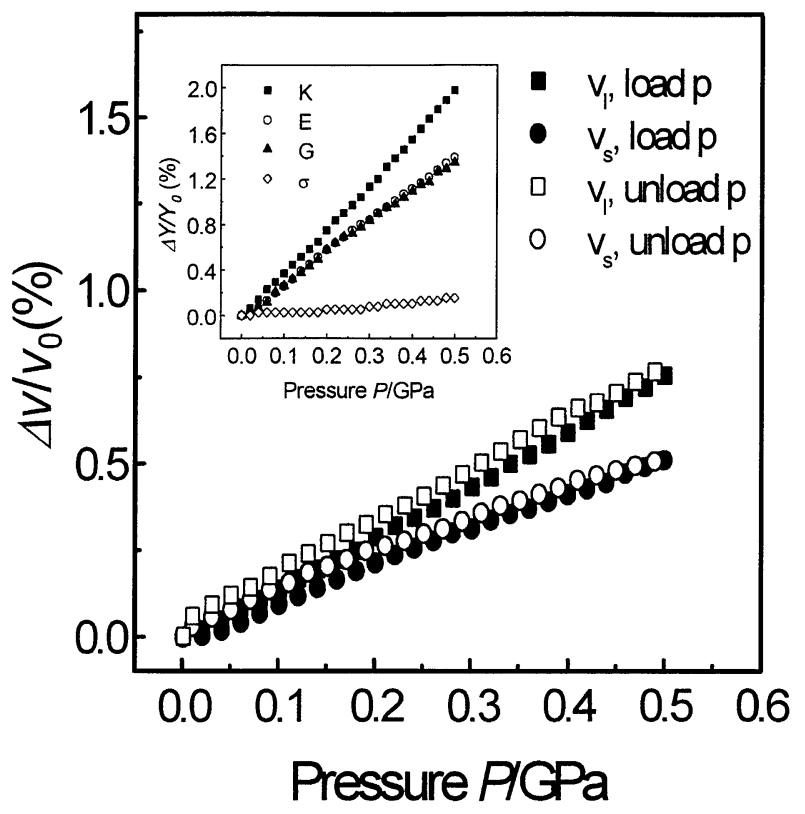

Fig. 3 Variation of longitudinal and transverse velocities of the $\mathrm{Pd}_{39} \mathrm{Ni}_{10} \mathrm{Cu}_{30} \mathrm{P}_{21} \mathrm{BMG}$ with pressure $\left(v=v_{1}, v_{\mathrm{s}}\right)$ at room temperatue.

of the BMGs. ${ }^{21)} d K / d P$ and $d G / d P$ of the two BMGs are positive, indicating the modulus stiffness under hydrostatic pressure.

Without phase transformation, the equations of state (EOS) of the BMGs can be described in terms of the Murnaghan form: ${ }^{23,24)}$

$$
P=\frac{K_{0}}{K_{0}^{\prime}}\left[\left(\frac{V_{0}}{V(p)}\right)^{K_{0}^{\prime}}-1\right]
$$

where $K_{0}$ and $K_{0}^{\prime}$ are the bulk modulus and its pressure derivation at zero pressure, $V_{0}$ are the volume at zero pressure. From Figs. 2, and 3, we obtain linear pressure dependence of $K: K=3.92 P+107.4$ for the $\mathrm{Zr}_{41} \mathrm{Ti}_{14} \mathrm{Cu}_{12.5} \mathrm{Ni}_{9} \mathrm{Be}_{22.5} \mathrm{C}_{1}$ BMG and $K=6.28 P+159.1$ for the $\mathrm{Pd}_{39} \mathrm{Ni}_{10} \mathrm{Cu}_{30} \mathrm{P}_{21}$ BMG. Accordingly, the isothermal EOS of the BMGs in the elastic region is described as:

$$
\begin{aligned}
& P=27.3\left[\left(\frac{V_{0}}{V(p)}\right)^{3.92}-1\right] \\
& P=25.4\left[\left(\frac{V_{0}}{V(p)}\right)^{6.28}-1\right] .
\end{aligned}
$$

Figure 4 shows the various pressure dependence of the volume change $V_{0} / V(P)$ of some amorphous materials and metals. Unlike other amorphous materials such as oxide glasses and amorphous carbon, ${ }^{25)}$ upon loading, smaller decrease in volume is induced within the experimental range of pressure in the $\mathrm{Zr}$ - and Pd-based BMGs with a smaller slope, as do crystalline metals. It is seen that the compression curve of the Pd-based BMG is close to those of crystalline Pd, Ni and $\mathrm{Cu}$ curves, ${ }^{26)}$ and interposed between them. An identical result can also be found in the $\mathrm{Zr}$-based BMG. Clearly, the compressibility of the BMGs exhibits an average behavior of those of the three metallic components. It is known that the compressibility of a solid is closely related to the nature of its atomic bonding and atomic configurations, ${ }^{26)}$ and thus Fig. 4 implies that the BMGs have analogous short-range structural

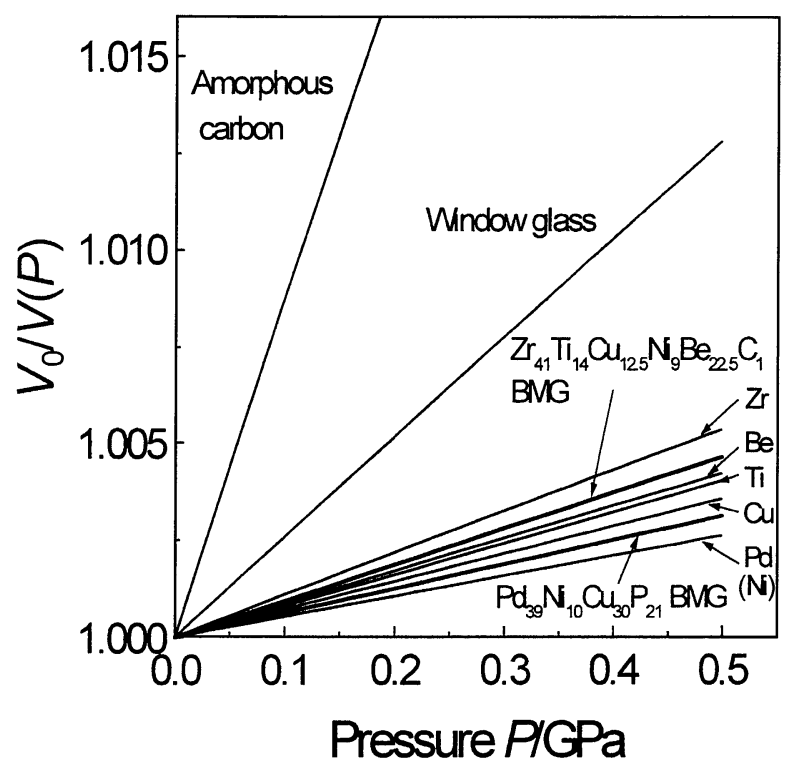

Fig. 4 Comparison of volume compression curves of various materials. $V_{0}$ is the volume under ambient pressure.

configurations to those of their metallic elements, whereas the existence of metalloid component $\mathrm{P}$ or $\mathrm{C}$ does not change the nature of metallic bonding. For the $\mathrm{Pd}_{39} \mathrm{Ni}_{10} \mathrm{Cu}_{30} \mathrm{P}_{21} \mathrm{BMG}$, $\mathrm{Pd}, \mathrm{Ni}$, and $\mathrm{Cu}$ are known to be of cubic close-packed arrangements, and thus it is reasonable to conclude that the same atomic configuration dominates the short-range order of the Pd-based BMG. The present results provide forceful evidence that the $\mathrm{Pd}_{39} \mathrm{Ni}_{10} \mathrm{Cu}_{30} \mathrm{P}_{21}$ BMG microscopically has close-packed short-range atomic configurations. For the $\mathrm{Zr}$ based BMG, due to the complexity of the structure of components, it is inferred that the atomic short-range configurations are of diversity in the BMG.

\subsection{Ultrasonic attenuation}

Ultrasonic attenuation measurement is a powerful tool to investigated the structural relaxation behavior in glassy systems, which is important to gain insight into the physical nature of glass formation, since slight atomic rearrangements can be monitored. ${ }^{27-29)}$ The ultrasonic attenuation coefficients of the longitudinal $\left(\alpha_{1}\right)$ and transverse $\left(\alpha_{\mathrm{s}}\right)$ waves at $10 \mathrm{MHz}$ in the $\mathrm{Zr}_{41} \mathrm{Ti}_{14} \mathrm{Cu}_{12.5} \mathrm{Ni}_{9} \mathrm{Be}_{22.5} \mathrm{C}_{1}$ and $\mathrm{Pd}_{39} \mathrm{Ni}_{10} \mathrm{Cu}_{30} \mathrm{P}_{21}$ BMGs are listed in Table 2 as well as those of the typical oxide glasses and conventional metallic glasses. One can see that the $\alpha_{1}$ and $\alpha_{\mathrm{t}}$ for the BMGs are much larger than those of the conventional metallic glasses ${ }^{30-33)}$ and smaller than

Table 2 The attenuation coefficient of the longitudinal and transverse $\left(\alpha_{1}, \alpha_{s}\right)$ and corrsponding ultrasonic velocities $\left(v_{1}, v_{s}\right)$ at $10 \mathrm{MHz}$ for $\mathrm{Zr}_{41} \mathrm{Ti}_{14} \mathrm{Cu}_{12.5} \mathrm{Ni}_{9} \mathrm{Be}_{22.5} \mathrm{C}_{1}$ and $\mathrm{Pd}_{39} \mathrm{Ni}_{10} \mathrm{Cu}_{30} \mathrm{P}_{21}$ BMGs, typical oxide glasses, and conventional metallic glasses.

\begin{tabular}{lccc}
\hline \multicolumn{1}{c}{ Sample } & $\alpha_{1}(\mathrm{~dB} / \mathrm{cm})$ & $\alpha_{\mathrm{s}}(\mathrm{dB} / \mathrm{cm})$ & Refs. \\
\hline $\mathrm{Zr}_{41} \mathrm{Ti}_{14} \mathrm{Cu}_{12.5} \mathrm{Ni}_{9} \mathrm{Be}_{22.5} \mathrm{C}_{1}$ & 1.72 & 1.71 & This \\
$\mathrm{Pd}_{39} \mathrm{Ni}_{10} \mathrm{Cu}_{30} \mathrm{P}_{21}$ & 2.74 & 0.6 & works \\
Window glass & 4.3 & 3.0 & $19)$ \\
Water-white glass & 4.3 & 5.4 & $19)$ \\
$\mathrm{Pd}_{79.5} \mathrm{Si}_{16.5} \mathrm{Cu}_{6}$ & $<0.1$ & $\sim 0.1$ & $32)$ \\
$\mathrm{Pd}_{79.5} \mathrm{Si}_{16.5} \mathrm{Ag}_{6}$ & $<0.002$ & $\sim 0.002$ & $33)$ \\
\hline
\end{tabular}




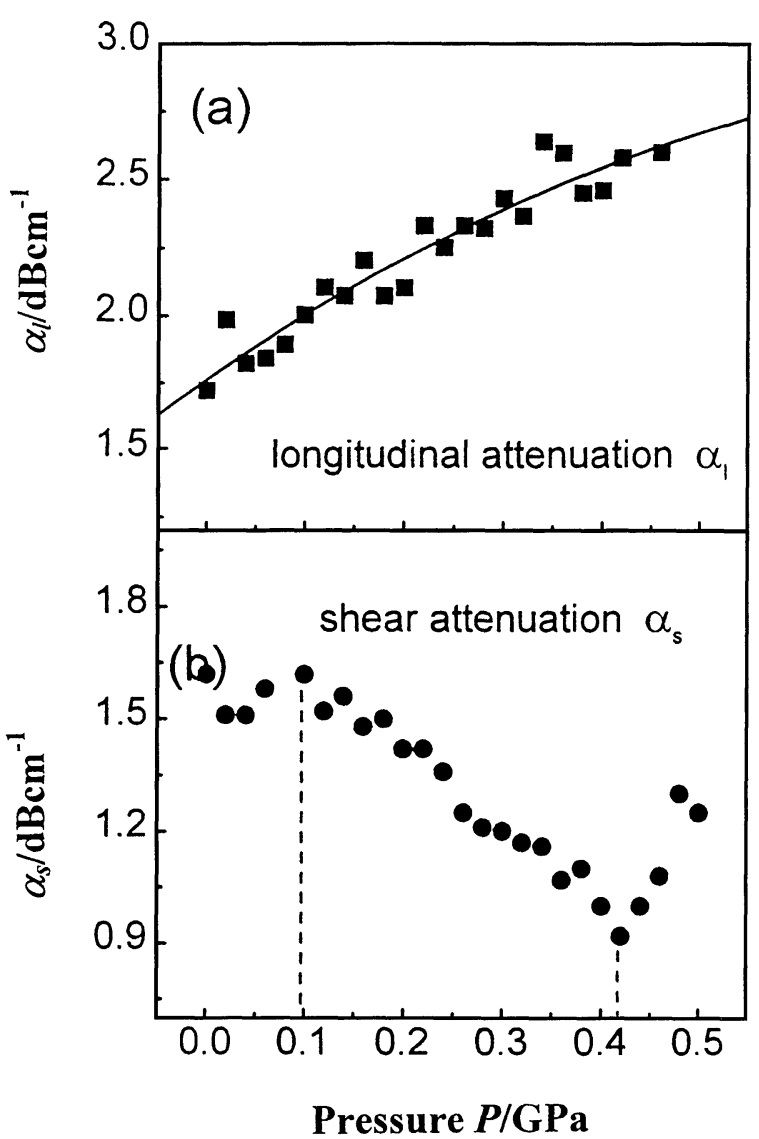

Fig. 5 Pressure dependence of the longiudinal (a) and transverse (b) ultrasonic waves attenuation in the $\mathrm{Zr}_{41} \mathrm{Ti}_{14} \mathrm{Cu}_{12.5} \mathrm{Ni}_{9} \mathrm{Be}_{22.5} \mathrm{C}_{1} \mathrm{BMG}$ measured at room temparature.

those of the oxide glasses. ${ }^{19,34)}$ This indicates that the BMGs have larger acoustic absorption compared to the conventional metallic glasses. It is known that the anharmonicity in a solid gives rise to an acoustic attenuation via so called Akkieser effect. $^{30,35)}$ The strong interatomic interaction (measured by Grueneisen parameter $\gamma$ ) results in the larger anharmonicity, which has been observed in the oxide glasses. ${ }^{36)}$ The oxide glasses with the stronger atomic bonding interaction have larger acoustic attenuation (amount to $\sim 4.3$ ). So, the ultrasonic attenuation behaviors are closely associated with the bonding forms of these glasses, and the denser packed atomic configurations of the $\mathrm{BMGs}^{5,7,8)}$ may result in much larger acoustic attenuation comparing with the conventional metallic glasses.

The pressure dependence of the $\alpha_{1}$ and $\alpha_{\mathrm{s}}$ in the two BMGs measured with a $10 \mathrm{MHz}$ carrying frequency is shown in Figs. 5 and 6, respectively. The data are reproducible under pressure cycle. For the $\mathrm{Zr}_{41} \mathrm{Ti}_{14} \mathrm{Cu}_{12.5} \mathrm{Ni}_{9} \mathrm{Be}_{22.5} \mathrm{C}_{1}$, the value of $\alpha_{1}$ increases with pressure, a similar behavior has also been observed in oxide glasses. ${ }^{19)}$ A remarkable feature for $\alpha_{\mathrm{s}}$ is observed that the pressure dependence of $\alpha_{\mathrm{s}}$ shows a nonmonotonically increasing tendency and reaches a minimum at $0.42 \mathrm{GPa}$, which is rather different from $\alpha_{1}$. However, more strikingly, the $\mathrm{Pd}_{39} \mathrm{Ni}_{10} \mathrm{Cu}_{30} \mathrm{P}_{21} \mathrm{BMG}$ shows a completely inverse case to the $\mathrm{Zr}_{41} \mathrm{Ti}_{14} \mathrm{Cu}_{12.5} \mathrm{Ni}_{9} \mathrm{Be}_{22.5} \mathrm{C}_{1} \mathrm{BMG}$ in the pressure dependence of $\alpha_{1}$ and $\alpha_{\mathrm{s}}$. For the $\mathrm{Pd}_{39} \mathrm{Ni}_{10} \mathrm{Cu}_{30} \mathrm{P}_{21}$ $\mathrm{BMG}, \alpha_{\mathrm{s}}$ monotonously and markedly increase with pressure, whereas the pressure dependence of $\alpha_{1}$ shows a minimum at

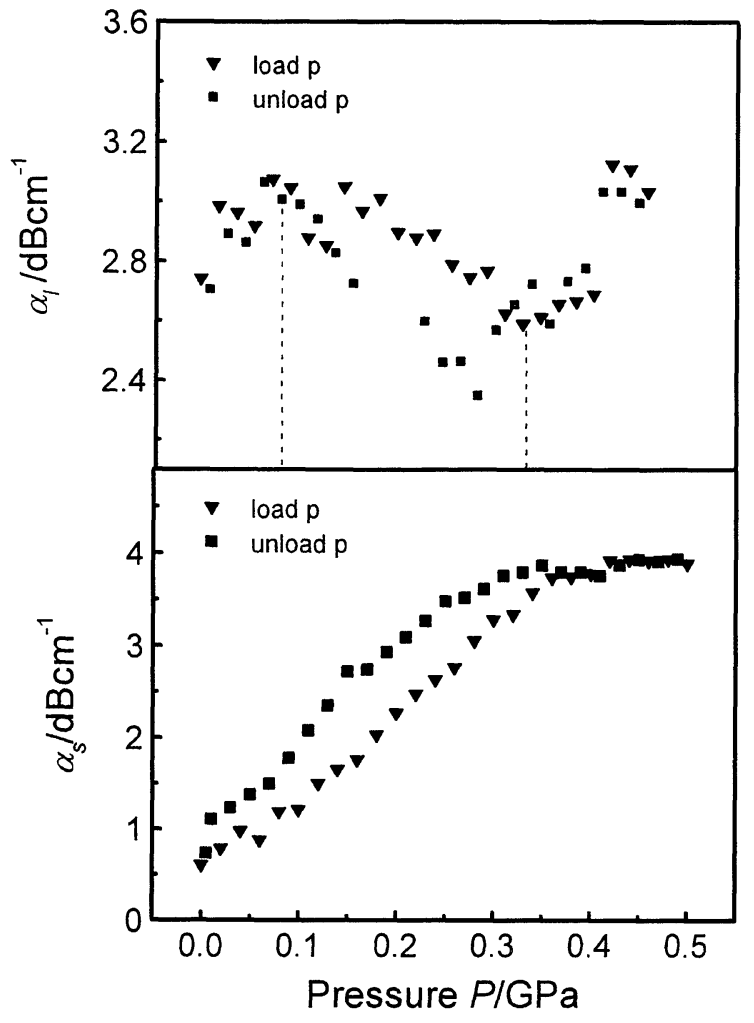

Fig. 6 Pressure dependence of the longiudinal (a) and transverse (b) ultrasonic waves attenuation in the $\mathrm{Pd}_{39} \mathrm{Ni}_{10} \mathrm{Cu}_{30} \mathrm{P}_{21} \mathrm{BMG}$ measured at room temparature.

about $0.36 \mathrm{GPa}$. Additionally, hysteresis effect can be observed in the $\mathrm{Pd}_{39} \mathrm{Ni}_{10} \mathrm{Cu}_{30} \mathrm{P}_{21} \mathrm{BMG}$. On the contrary, no hysteresis effect is exhibited in the $\mathrm{Zr}_{41} \mathrm{Ti}_{14} \mathrm{Cu}_{12.5} \mathrm{Ni}_{9} \mathrm{Be}_{22.5} \mathrm{C}_{1}$ $\mathrm{BMG}$. In general, the oxide glasses and the conventional MGs have similar pressure and temperature dependence of the longitudinal and transverse acoustic attenuation, where a monotonously increasing tendency is often found. ${ }^{19,36)}$ Moreover, the attenuation in the conventional MGs follows a frequency-squared $\left(f^{2}\right)$ law, e.g., for $\mathrm{Pd}_{79.5} \mathrm{Cu}_{6} \mathrm{Si}_{16.5}$ and $\mathrm{Pd}_{79.5} \mathrm{Ag}_{6} \mathrm{Si}_{16.5} \mathrm{MGs}, \alpha(\mathrm{dB} / \mathrm{cm})$ ranges from $\sim 0.7 \times 10^{-3} f^{2}$ to $1.4 \times 10^{-3} f^{2}{ }^{30,31)}$ The unique pressure dependence of attenuation in the two BMGs may be related to the different kinetics behaviors of atomic configurations under pressure. The pressure-dependent attenuation behaviors indicate the occurrence of a pressure-induced structural relaxation.

\subsection{Pressure effects on the glass transition}

The basic understanding of the glass transition is still an unresolved problem. ${ }^{28,37)}$ On one hand, many glass formers display unusual thermodynamic properties near the glass transition such as entropy, enthalpy, and volume; on the other hand, the transition process reflects the freezing-in of liquidlike modes and is thus related to the slowing dynamics. ${ }^{38-41)}$ The newly developed TMDSC technique provides a powerful tool to investigate the glass transition with two additional predominant features, one being that irreversible and reversible heat flow can be separated from total heat flow, the other that capacity can be accurately derived from the reversible heat flow signal. ${ }^{42,43)}$ Endothermic valleys are often shown from irreversible heat flow curves upon glass transition. It is known that the endothermic valleys reflect enthalpy recovery 


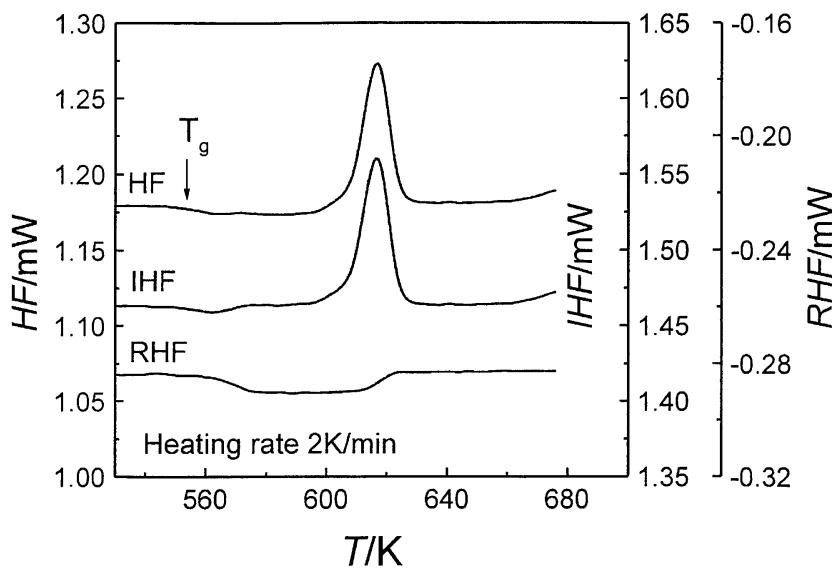

Fig. 7 The TMDSC curves of the unrelaxed $\mathrm{Pd}_{39} \mathrm{Ni}_{10} \mathrm{Cu}_{30} \mathrm{P}_{21}$ bulk metallic glass. HF, IHF, and RHF stand for the total, irreversible and reversible heat flow respectively.

processes, where the released heat during the preceding relaxation is recovered upon the glass transition when reheating the samples. ${ }^{44,45)}$ Thus, According to the recovery enthalpy, the degree of the structural relaxation in a glass can be evaluated.

Figure 7 shows a typical TMDSC result of an unrelaxed $\mathrm{Pd}_{39} \mathrm{Ni}_{10} \mathrm{Cu}_{30} \mathrm{P}_{21}$ BMG with a total heat flow curve and its irreversible and reversible components. The glass transition is observed near $560 \mathrm{~K}$, around which a small endothermic valley in the irreversible heat flow curve and a drop of heat flow in the reversible curve are exhibited, respectively. From the irreversible endothermic valley, the irreversible enthalpy $\Delta H_{\mathrm{IHF}}$ is determined to be $\sim 1.4 \mathrm{~J} / \mathrm{g}$. This value corresponds to the recovery enthalpy, which is equivalent to the released heat during relaxation (relaxation enthalpy). Compared to the remarkable crystallization enthalpy of $\sim 32.2 \mathrm{~J} / \mathrm{g}$ obtained from the subsequent crystallization peak, the relaxation enthalpy is rather small. This is ascribed to the occurrence of atomic short-range ordering during relaxation, different from the atomic long-range rearrangements. ${ }^{1,27)}$ One can see from Fig. 7 that an irreversible and a reversible transition processes are simultaneously involved in the glass transition of the unrelaxed BMG, whereas the subsequent remarkable crystallization behavior, as we know, is just irreversible.

Figure 8 exhibits the pressure dependence on the irreversible contribution to the glass transition in the relaxed samples. The irreversible heat flow curves are shown in the inset of Fig. 8. The shade regions in the inset manifest the irreversible endothermic behaviors in the differently processed samples. For the relaxed samples, the irreversible recovery enthalpy should mainly originate from the released heat during the isothermal relaxation at high pressure. It can be seen in Fig. 8 that $\Delta H_{\mathrm{IHF}}$ increases with the relaxation pressure, which indicates that increasing pressure induces deeper relaxation. It is inferred that more frozen-in enthalpy in the glassy samples is released after the relaxation at higher pressure, and then lower enthalpic states are attained. Within the experimental pressure range, an approximately linear correlation between $\Delta H_{\mathrm{IHF}}$ and pressure can be well described with a slope of $\sim 0.37 \mathrm{~J} / \mathrm{g}^{*} \mathrm{GPa}$.

The specific heat capacity $C_{\mathrm{p}}$ curves, which are derived from the reversible heat flow curves, of the differently processed $\mathrm{Pd}_{39} \mathrm{Ni}_{10} \mathrm{Cu}_{30} \mathrm{P}_{21}$ BMG samples are shown in Fig. 9,

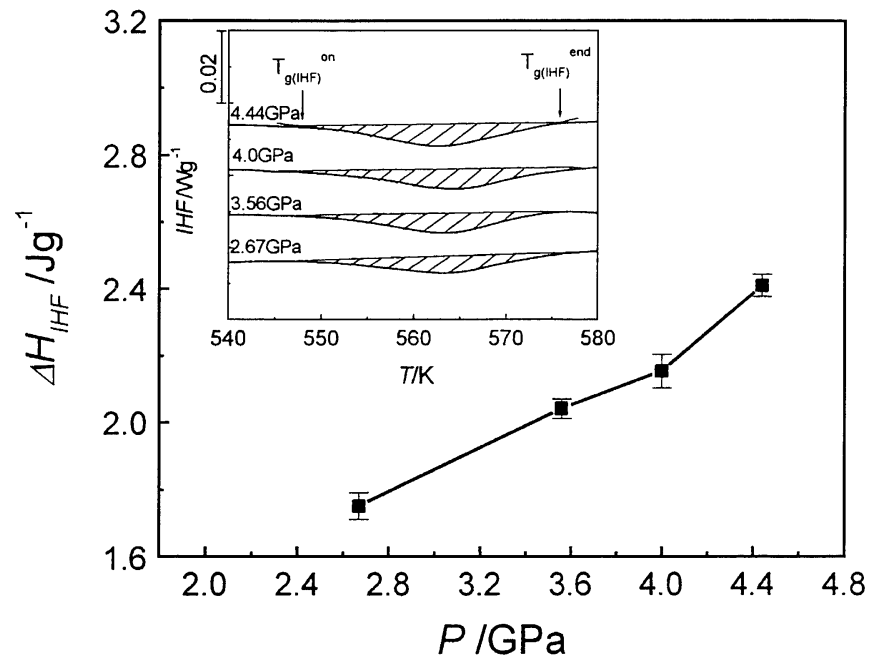

Fig. 8 Dependence of the relaxation pressure on the irreversible recovery enthalpy $\Delta H_{\mathrm{IHF}}$ involved in the glass transition of the relaxed $\mathrm{Pd}_{39} \mathrm{Ni}_{10} \mathrm{Cu}_{30} \mathrm{P}_{21}$ bulk metallic glass. The irreversible heat flow (IHF) curves are shown in the inset.

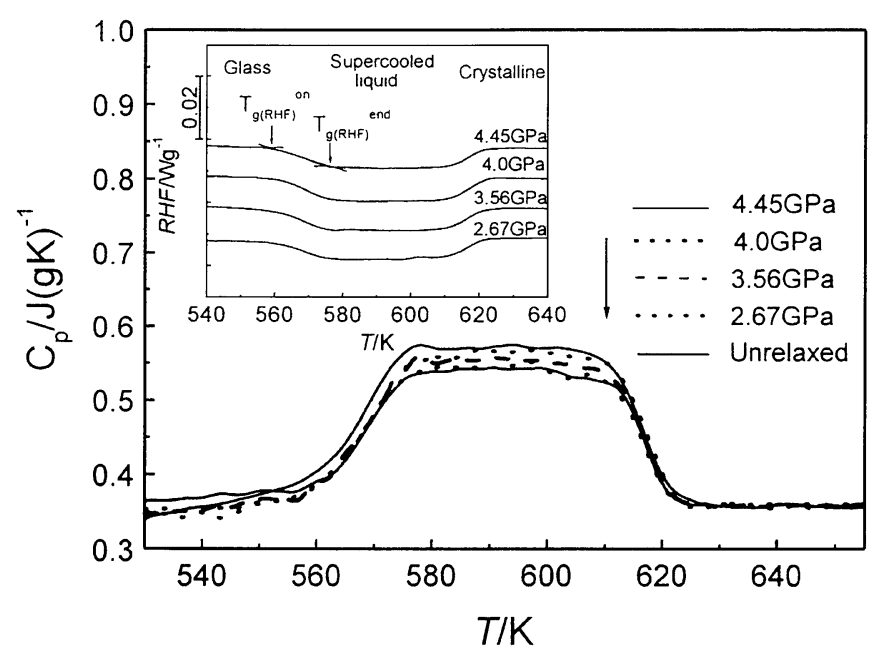

Fig. 9 Specific heat capacity $C_{\mathrm{p}}$ curves of the differently processed samples as a function of relaxation pressure. The reversible heat flow (RHF) curves are shown in the inset.

indicating their pressure dependence. The reversible heat flow curves are given in the inset of Fig. 9. It is found that the relaxed samples show a slightly but monotonously increase in the capacity of the supercooled liquid when the relaxation pressure is above $\sim 3 \mathrm{GPa}$. Roughly, after the sample is relaxed at $4.45 \mathrm{GPa}$, the capacity of the supercooled liquid increases by $\sim 5 \%$ relative to that of the unrelaxed sample. This indicates that the relaxation processes under high pressure bring about the detectable thermodynamic change in the reversible transitions. So far, the cause responsible for the pressure-induced increase of the capacity of the supercooled liquid is not clear. Structural changes upon the glass transition may be involved among the samples relaxed at the different pressures, and then the supercooled liquids with different enthalpic states are attained. We argue that the relaxation at high-pressure (above $\sim 3 \mathrm{GPa}$ ) may cause the deviation of the glass transition from the glassy states to an ergodic supercooled liquid state in the BMG. 


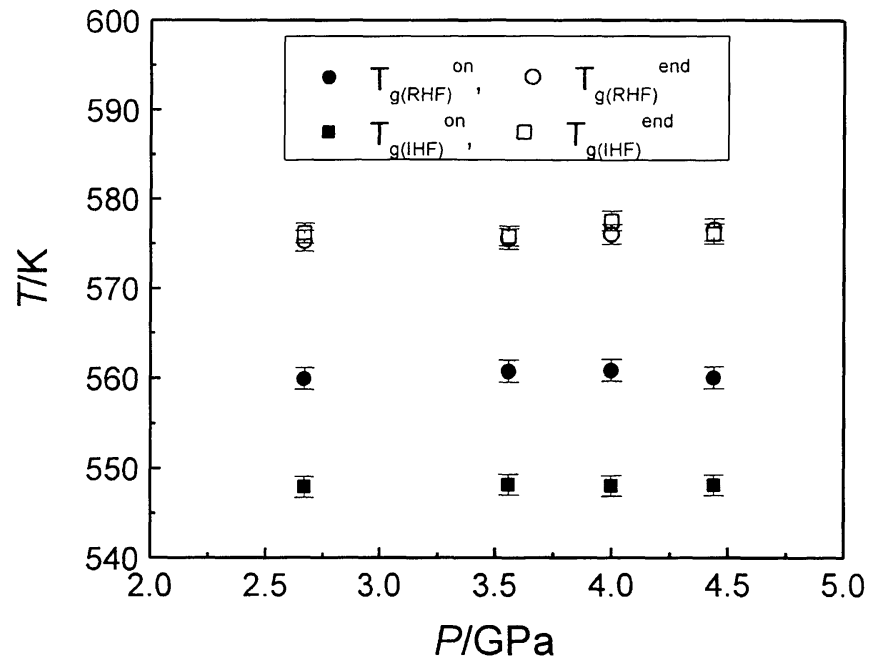

Fig. 10 Pressure dependence of the onset and end temperatures in the irreversible and reversible processes involved in the glass transition. $T_{\mathrm{g}(\mathrm{IHF})}^{\mathrm{on}}$, $T_{\mathrm{g}(\mathrm{RHF})}^{\mathrm{on}}$ stand for the onset temperatures in the irreversible enthalpy recovery and the reversible transition respectively, and $T_{\mathrm{g}(\mathrm{IHF})}^{\mathrm{end}}, T_{\mathrm{g}(\mathrm{RHF})}^{\mathrm{end}}$ for the end temperatures.

The onset and end glass transition temperatures in the irreversible and reversible processes are marked in the two insets of Figs. 8 and 9 to demonstrate the pressure effect on the kinetics of the glass transition of the BMG. $T_{\mathrm{g}(\mathrm{IHF})}^{\mathrm{on}}, T_{\mathrm{g}(\mathrm{RHF})}^{\mathrm{on}}$ are referred to as the onset temperatures in the irreversible enthalpy recovery and the reversible transition respectively, and $T_{\mathrm{g}(\mathrm{IHF})}^{\mathrm{end}}, T_{\mathrm{g}(\mathrm{RHF})}^{\mathrm{end}}$ as the end temperatures. Figure 10 shows the pressure dependence of these characteristic temperatures. For the relaxed samples, no marked pressure effect is seen on the characteristic temperatures within the measurement error, and $T_{\mathrm{g}(\mathrm{IHF})}^{\mathrm{on}}, T_{\mathrm{g}(\mathrm{RHF})}^{\mathrm{on}}, T_{\mathrm{g}(\mathrm{IHF})}^{\text {end }}$ and $T_{\mathrm{g}(\mathrm{RHF})}^{\mathrm{end}}$ roughly keep constants of $548,560,576$, and $576 \mathrm{~K}$, respectively. It is known that when heating, the glass transition is a relaxation process towards a metastable supercooled liquid from a glassy state, which depend on the crossing of an experimental time scale and the time scale for relaxation. ${ }^{40,46)}$ And thus, the magnitude of the transition interval is a result of the competition between the two aspects. In view of the identical heating rate during the measurements, it seems that the pressure-induced structural densification does not impede the relaxation rate towards the supercooled liquid in the differently processed samples. In addition, two significant features are found in Fig. 10. First, the irreversible enthalpy recovery always takes place about $12 \mathrm{~K}$ earlier than the reversible transition. This indicates that the enthalpy recovery begins when the samples still remain glassy states. Consequently, the enthalpy recovery processes can be divided into two parts, the beginning relaxation towards the metastable glassy state and the subsequent one towards the metastable supercooled liquid. Below $T_{\mathrm{g}(\mathrm{RHF})}^{\mathrm{on}}$ of about $560 \mathrm{~K}$, the enthalpy recovery is dominated by the approach to the metastable glass. The second feature is that the irreversible and the reversible process end simultaneously at about $576 \mathrm{~K}$ in the relaxed samples, which indicates the complete arrival at the metastable suprecooled liquid.

Comparing the two figures, it is clear that the pressure dependence of the capacity of the supercooled liquid is out of step with that of the irreversible recovery enthalpy. Only when the degree of the relaxation is high enough, it can cause the change of the reversible transition behavior. The pressureinduced increases of the irreversible recovery enthalpy and the capacity of the supercooled liquid confirm that the relaxation at high-pressure thermodynamically changes the glass transition of the BMG. Besides, it is observed from Fig. 10 that within the experimental pressure range, the relaxation processes does not bring about marked changes in the time scales for the irreversible enthalpy recovery and the reversible transition. Considering the relatively pronounced increase in $\Delta H_{\mathrm{IHF}}$ and $C_{\mathrm{p}}$ with pressure, it is possible that the kinetics of the glass transition in the $\mathrm{Pd}_{39} \mathrm{Ni}_{10} \mathrm{Cu}_{30} \mathrm{P}_{21} \mathrm{BMG}$ has a weak dependence on the pressure-induced thermodynamic changes.

\section{Summary}

(1) A link of the elastic properties with the GFA and the microstructural characteristics of metallic glasses is established on the basis of the elastic properties measurements of the $\mathrm{Zr}_{41} \mathrm{Ti}_{14} \mathrm{Cu}_{12.5} \mathrm{Ni}_{9} \mathrm{Be}_{22.5} \mathrm{C}_{1}$ and $\mathrm{Pd}_{39} \mathrm{Ni}_{10} \mathrm{Cu}_{30} \mathrm{P}_{21}$ BMGs. The positive pressure derivatives $d K / d p$ and $d G / d p$ indicate the pressure-induced modulus stiffness. The equations of state of the two BMGs are established. It is revealed that the atomic short-range configurations in the BMGs are dependent on the atomic configurations of their metallic components.

(2) The $\mathrm{Zr}_{41} \mathrm{Ti}_{14} \mathrm{Cu}_{12.5} \mathrm{Ni}_{9} \mathrm{Be}_{22.5} \mathrm{C}_{1}$ and $\mathrm{Pd}_{39} \mathrm{Ni}_{10} \mathrm{Cu}_{30} \mathrm{P}_{21}$ $\mathrm{BMGs}$ show higher acoustic loss than that of the conventional MGs, which is ascribed to larger anharmonicity. The two BMGs exhibit completely different pressure dependence of the ultrasonic attenuation in longitudinal and transverse waves.

(3) The pressure dependence of the irreversible enthalpy recovery and the reversible transition is exhibited upon the glass transition of the $\mathrm{Pd}_{39} \mathrm{Ni}_{10} \mathrm{Cu}_{30} \mathrm{P}_{21} \mathrm{BMG}$. Within the experimental pressure range from $\sim 2.7$ to $\sim 4.5 \mathrm{GPa}$, the irreversible recovery enthalpy approximately linearly increases with the relaxation pressure. Above $\sim 3 \mathrm{GPa}$, the relaxation at high pressure causes the increase of the capacity of the supercooled liquid. However, the relaxation processes do not produce marked changes on the kinetics of the irreversible and reversible transition.

\section{Acknowledgement}

This work was supported by the National Natural Science Foundation of China under Grant No. 59889102, 59925101, 59871059,19874075 , and by Chinese National Microgravity Laboratory (Pan-Yu-95-34).

\section{REFERENCES}

1) H. S. Chen: Rep. Prog. Phys. 43 (1980) 23.

2) A. L. Greer: Science 267 (1995) 1947.

3) A. Peker and W. L. Johnson: Appl. Phys. Lett. 63 (1993) 2342.

4) N. Nishiyama and A. Inoue: Mater. Trans., JIM 37 (1996) 1531.

5) W. H. Wang, Q. Wei and S. Friedrich: Phys. Rev. B 57 (1998) 8211.

6) A. Meyer, R. Busch and H. Schober: Phys. Rev. Lett. 83 (1999) 5027.

7) W. L. Johnson: Mater. Sci. Forum 225-227 (1996) 35.

8) A. Inoue: Bulk metallic glasses, Vol. 6 in Materials Science Fundations, (Trans. Tech. Ltd. 1999).

9) X. P. Tang, U. Geyer, R. Busch, W. L. Johnson and Y. Wu: Nature 402 (1999) 160. 
10) L. Y. Gao, Y. Xue, F. Chen, Q. Xiong, R. L. Meng, D. Ramirez and H. K. Mao: Physica C 235 (1994) 1493.

11) M. Akaishi, H. Kanda and S. Yamaoka: Science 259 (1993) 1592.

12) L. J. Parker, T. Atou and J. V. Badding: Science 273(5) (1996) 95.

13) W. K. Wang, H. Iwasaki and K. Fukamichi: J. Mater. Sci. 15 (1980) 2701.

14) W. K. Wang: Progress in Physics 4 (1984) 525 (in Chinese).

15) W. H. Wang, R. J. Wang, F. Y. Li, D. Q. Zhao and M. X. Pan: Appl. Phys. Lett. 74 (1999) 1803.

16) Li Min Wang, W. H. Wang, R. J. Wang, Z. J. Zhan, D. Y. Dai, L. L. Sun and W. K. Wang: Appl. Phys. Lett. 77 (2000) 1147.

17) Richard Cook: J. Acous. Soc. America 29 (1957) 445.

18) E. Schreiber: Elastic Constants and Their Measurement, (McGrawHill, New York, 1973).

19) R. J. Wang, F. Y. Li, J. Xu and H. S. Xie: J. High Press. Phys. 8 (1994) 177 (in Chinese).

20) K. Kondo, S. Lio and A. Sawaoka: J. Appl. Phys. 52 (1981) 2826.

21) H. S. Chen, J. T. Krause and E. Coleman: J. Non-Cryst. Solids 18 (1975) 157.

22) J. F. Wang and R. J. Wang: J. High Press. Phys. 9 (1995) 235 (in Chinese).

23) F. D. Murnaghan: Finite Deformation of an Elastic Solid, (John Wiley \& Sons, INC. New York, 1951).

24) M. H. Manghnani and S. Akimoto: High-Pressure Research, (Academic Press, INC. New York, 1977).

25) J. F. Wang, R. J. Wang and S. A. He: J. High Press. Phys. 2 (1988) 34 (in Chinese).

26) P. W. Bridgman: The Physic of High Pressure, (G. Bell and Sons, LTD.
London, 1931).

27) A. L. Greer: J.Non-cryst. Solids. 61\&62 (1984) 737.

28) J. Jckle: Rep. Prog. Phys. 49 (1986) 171.

29) G. W. Koebrugge, J. Sietsma and A. Van den Beukel: Acta. Metall. Matter. 40 (1992) 753.

30) R. N. Thurston and K. Brugger: Phys. Rev. 133 (1964) A1604.

31) R. Devanatha, N. Q. Lam, P. R. Okamoto and M. Meshii: Phys. Rev. B 48 (1993) 42.

32) L. R. Testardi, J. T. Krause and H. S. Chen: Phys. Rev. B 8 (1973) 4464.

33) M. Dutoit and H. S. Chen: Appl. Phys. Lett. 23 (1973) 357.

34) D. Weaier, M. F. Ashby, J. Logan and M. J. Weins: Acta. Metall. 19 (1971) 779.

35) H. H. Barrett and M. G. Holland: Phys. Rev. B 1 (1970) 1.

36) J. Fabian and P. Allen: Phys. Rev. Lett. 82 (1999) 1478.

37) P. W. Anderson: Science 267 (1995) 1610

38) W. Kauzmann: Chem. Rev. 43 (1948) 219.

39) N. Menon and S. R. Nagel: Phys. Rev. Lett. 74 (1975) 1230.

40) M. D. Ediger, C. A. Angell and S. R. Nagel: J. Phys. Chem. 100 (1996) 13200.

41) S. Torquato: Nature 405 (2000) 521.

42) A. Boller, C. Schich and B. Wunderlich: Thermochim Acta. 266 (1995) 97.

43) X. Hu, T. B. Tan, Y. Li, G. Wilde and J. H. Perepezko: J. Non-Cryst. Solids 260 (1999) 228.

44) R. Bush and W. L. Johnson: Appl. Phys. Lett. 72 (1998) 2695.

45) K. Samwer, R. Busch and W. L. Johnson: Phys. Rev. Lett. 82 (1999) 580 .

46) Marc L. Mansfield: J. Chem. Phys. 103 (1995) 8124. 